\title{
Preconscious Control of Stereotype Activation Through Chronic Egalitarian Goals
}

\author{
Grordon B. Moskowitz \\ Princeton University
}

\author{
Peter M. Gollwitzer, Wolfgang Wasel, \\ and Bernd Schaal \\ University of Konstanz
}

\begin{abstract}
This research shows stereotype activation is controlled by chronic egalitarian goals. In the first 2 studies it was found that the stereotype of women is equally available to individuals with and without chronic goals, and the discriminant validity of the concept of egalitarian goals was established. In the next 2 experiments, differences in stereotype activation as a function of this individual difference were found In Study 3, participants read attributes following stereotypical primes. Facilitated response times to stereotypical attributes were found for nonchronics but not for chronics. This lack of facilitation occurred at stimuius onset asynchronies (SOAs) where effortful correction processes could not operate, demonstrating preconscious control of stereotype activation due to chronic goals. In Study 4, inhibition of the stereotype was found at an SOA where effortful processes of stereotype suppression could not operate. The data reveal that goals are activated and used preconsciously to prevent stereotype activation, demonstrating both the controllability of stereotype activation and the implicit role of goals in cognitive control.
\end{abstract}

The current research addresses an important question for understanding both the nature of stereotyping and the nature of cognitive control: Can one's commitment to a goal lead to control over the preconscious stages in which categorization occurs and stereotypes are activated? Because of the ease with which stereotypes are used to encode behaviors from and information about members of stigmatized groups, as well as the often unconscious and implicit nature of these processes, the answer to this question has been regarded as "No" (for reviews, see Hamilton \& Sherman, 1994; Stangor \& Lange, 1994; Von Hippel, Sekaquaptewa, \& Vargas, 1995). Devine (1989, p. 6) referred to a stereotype as "a welllearned set of associations (Dovidio, Evans, \& Tyler, 1986) that is automatically activated...this unintentional activation of the stereotype is equally strong and equally inescapable for highand low-prejudice persons." Thus, because "automatic processes ... do not require conscious effort" and "a crucial component of automatic processes is their inescapability; they occur despite deliberate attempts to bypass or ignore them" (Devine, 1989 , p. 6), stereotype activation has been deemed uncontrollable. It is our aim to establish that stereotype activation is controlled

Gordon B. Moskowitz, Department of Psychology, Princeton University; Peter M. Gollwitzer, Wolfgang Wasel, and Bernd Schaal, Department of Psychology, University of Konstanz, Konstanz, Germany.

Portions of this manuscript were presented at the 8th Annual Conference of the American Psychological Society, San Francisco, July 1996; see Moskowitz, Wasel, Gollwitzer, and Schaal (1996).

This research began when Gordon B. Moskowitz was at the University of Konstanz for the 1993-1994 academic year.

Correspondence concerning this article should be addressed to Gordon B. Moskowitz, Department of Psychology, Princeton University, Green Hall, Princeton, New Jersey 08544. Electronic mail may be sent to gordonmo@princeton.edu. through intent, and that intent operates in a preconscious, resourceindependent fashion. Consistent with Moskowitz and Sussman's (1999) demonstration that activated goals preconsciously direct selective attention and Wegner's (1994) belief that mental control (with practice) can be automatized, we propose that volition, in the form of chronic egalitarian goals, leads to the passive and preconscious control of stereotype activation. Rather than conceiving of goals as operating through effort and cognitive control as equivalent with conscious forms of "mental decontamination," it is proposed that goals intervene at the level of construct activation to exert passive control.

Devine (1989) described stereotyping with a two-process dissociation model. The first process is stereotype activation, and it is seen as automatic and inevitable. The second process is stereotype application, and it is seen as deliberate and controlled; there is inhibition of the automatically activated stereotype and activation of personal beliefs that are counter to the stereotype. Thus, Devine introduced two distinctions: First, stereotype activation and stereotype use are separate processes; second, cultural stereotypes and personal beliefs can be different cognitive structures. By pointing out the distinction between culturally shared stereotypes and personal beliefs, Devine defined a dimension along which individual differences can be identified. High- versus low-prejudice people differ in a motivational state, where low-prejudiced persons are said to be motivated to correct and adjust judgments for the impact of activated stereotypes. Low-prejudice people are characterized by a large difference between their personal beliefs and the cultural stereotype, and for these people there is a greater motivation to correct the automatically activated cultural stereotype. These people can be contrasted with high-prejudiced persons, who do not try to correct for stereotype use. 


\section{Preconscious Control Versus Effortful Correction} (Dissociation)

In making this distinction between high- and low-prejudiced persons, the focus has been on individual differences in the effortful use of debiasing or correction strategies, in which the lowprejudiced person deliberately attempts to remove the effects of an automatically activated stereotype. The dissociation process is said to be initiated through awareness that one is not meeting some standard of accuracy and fairness in social judgments (see also Myrdal's, 1944, discussion of the "American dilemma"). Producing a stereotype-free response requires that people have either an explicit motivation to be egalitarian or the phenomenological experience of feelings such as compunction (Devine, Monteith, Zuwerink, \& Elliot, 1991), hypocrisy (Stone, Wiegand, Cooper, \& Aronson, 1997), self-insight (Allport, 1954), or conflict (Myrdal, 1944). If people meet all three criteria of being aware of bias, being motivated to be nonbiased, and being furnished with cognitive resources to carry out the required mental work, people can remove the impact of activated stereotypes from final judgments (e.g., Fiske \& Neuberg, 1990; Moskowitz et al., 1996; E. P. Thompson, Roman, Moskowitz, Chaiken, \& Bargh, 1994).

However, such correction processes are not infallible in eliminating the effects of stereotypes. The awareness, motivation, and capacity that correction processes require may be interfered with, and stereotyping can persist. ${ }^{1}$ Because dissociation has a corrective nature (stereotypic thoughts are removed from final responses), one may denounce stereotyping but be imperfect in the ability to live up to what is professed. Unlike the dissociation model, it is posited here that effortful processes (linked to awareness of bias and feelings of guilt) are not the only way in which low-prejudice people remain stereotype-free. Rather, we suggest an additional, effortless, preconscious form of cognitive control may operate that determines whether stereotypes are activated to start with. Chronic egalitarians, whose low-prejudice goals are furnished with strong commitment, can be distinguished from those who simply articulate low-prejudice beliefs without commitment. For chronics, the egalitarian goal may be habitualized and lead to stereotype control that is of a preventative, rather than a corrective, nature.

The proposed individual difference in commitment to the goal of being egalitarian, fair, tolerant, and open-minded allows for an extension of (and modification to) the dissociation model so that (a) stereotype activation need not be conceived of as inevitable, and (b) stereotype control need not be conceived of as effortful and linked to one's awareness of bias and the experience of feelings such as compunction. Holding a chronic egalitarian goal can lead one to strive repeatedly for attainment of the goal, and it can lead to activation of the goal whenever a goal-relevant person is encountered. Thus, the goal of being egalitarian would operate preconsciously -it need not require awareness or effort.

\section{Goal Influences on Stereotype Activation: Auto-Motives and Chronic Goals}

Social-cognitive research suggests that not only trait categories and stereotypes but goals can be automatically activated in the early, inferential stages of person perception. Persistence in pursuit of a goal over time can lead to that goal being chronically accessible. According to Bargh (1990), goals become chronically ac- cessible through their frequent and committed pursuit. Despite the fact that goal strivings stem from an initial conscious goal intention, the repeated pairing of a goal with a set of situations leads to the eventual movement of goal pursuit from consciousness-the goal would become chronically accessible, anc this heightened accessibility would mean that the activation of the goal would no longer require the conscious intent to link goal striving to an environmental stimulus. Rather, the goal would be activated when appropriate environmental features are encountered (Bargh \& Gollwitzer, 1994), with the goal's activation being preconscious. Thus, goals are knowledge structures (Bargh, 1990; Kruglanski, 1996) and, like other knowledge structures, can be unconsciously activated (Bargh, Gollwitzer, Chai, \& Barndollar, 1998; Chartrand \& Bargh, 1996). As with knowledge structures, the greater the accessibility of the category, the less input required for the category to be activated (Bruner, 1957). Once activated, a construct (either a semantic or a goal construct) should be capable of capturing relevant stimuli and determining the nature of categorization (e.g., Bruner, 1957; Higgins, Rholes, \& Jones, 1977; Moskowitz \& Skurnik, 1999).

Bargh (1990) termed goals that are activated by an environmental stimulus auto-motives. This is similar to Ach's (1935) belief that an intention that was repeatedly carried out in a particular situation becomes automatically activated whenever this situation is encountered. Self-regulation thus is not only a matter of consciousness but is also contributed to by preconscious processes (see also Bargh, 1997). If the auto-motive model is applied to stereotype activation, persons holding a chronic goal to be egalitarian toward a particular group could unconsciously have an egalitarian goal activated when they perceive a member of this group. The activation of stereotypes that might occur for people without an egalitarian goal would be controlled by persons with chronic goals. In such cases, nonstereotypic, stimulus-relevant, semantic categories (e.g., doctor, cyclist, janitor, etc.) and goals could be more dominant than the stereotype and serve to capture the stimulus. ${ }^{2}$ This activation would be nonconscious and effective because of the increased accessibility that results from a long history of repeated activation.

The fact that some individuals can control stereotype activation does not mean we are implying that stereotyping is not passive. However, the lack of awareness of a process such as stereotype activation does not mean that it cannot be controlled through

\footnotetext{
'For example, one may shield insight from reaching consciousness to prevent the experience of guilt; goals other than egalitarianism may predominate; the press of the situation may prevent one from working toward bias-free responses; given a lack of commitment to egalitarianism, obstacles to goal pursuit may lead one to disengage from the pursuit of bias-free responses and to rationalize, rather than correct, stereotypes.

${ }^{2}$ We do not mean to imply here that the only way to become egalitarian is to overcome socialization experiences. The possibility that egalitarian societies may exist or that egalitarian families may shelter children from societal forces and raise them according to principles of egalitarianism is not discounted. It is simply noted that most cultures socialize children with notions of in-group and out-group and that goals can lead these experiences to be challenged.
} 
intent. ${ }^{3}$ Despite the fact that the English language vernacular equates intent with conscious and effortful forms of pursuing a desired end state, volition can be exerted preconsciously. A passive process like stereotype activation could be controlled by goal pursuit, which could be activated as passively as stereotype activation.

Bargh $(1989,1994)$ has distinguished between varieties of automaticity in cognitive processing, ranging from the preconscious (characterized by a lack of awareness of the instigating stimuli, the lack of a specific goal initiating the process, attentional resources not being required, and the inability to control the processes from occurring) to the intended. Stereotype activation has generally been regarded as an exemplar of preconscious automaticity. The nontrivial implication that arises from that classification is it means stereotype activation cannot be prevented; the only route to controlling stereotyping is to prevent stereotype use after activation. If stereotype activation was instead categorized as a goaldependent form of automaticity, it could still be described as operating without awareness or intent, but we would be forced to add notions of its controllability. This would suggest additional ways to control the effects of stereotypes, such as controlling stereotype activation.

\section{Assessing Chronic Egalitarian Goals Through Self-Completion Strivings}

In past research, experimenters asserting stereotype activation is inescapable labeled people as high and low in prejudice on the basis of self-reports from attitude scales (e.g., the Modern Racism Scale; McConahay, Hardee, \& Batts, 1981). However, such measures assess beliefs, not motivation. Our intent was to examine not prejudiced beliefs but chronic goal orientations. This was done using a procedure developed from the logic of symbolic selfcompletion theory. Wicklund and Gollwitzer (1982; Brunstein \& Gollwitzer, 1996; Gollwitzer \& Wicklund, 1985; Gollwitzer \& Kirchhof, 1998) posited that people conceive of aspects of the self in terms of goals. Not only do people think of themselves as possessing certain attributes (e.g., holding the self-concept of being smart, socially sensitive, or egalitarian with respect to members of certain groups) to a smaller or larger degree; rather, they also set the goal of becoming smart, socially sensitive, or egalitarian. If people commit themselves to such self-defining goals, they are expected to make use of available opportunities to express the goal and to hold on to it even in the face of hindrances, barriers, and difficulties. Failure to see oneself as possessing the attributes of the aspired-to identity leads to feelings of incompleteness, an aversive self-evaluative state. People try to alleviate this state by seeking evidence that they possess the desired attributes-they strive to possess symbols of self-completion (e.g., Gollwitzer, Wicklund, \& Hilton, 1982). When one fails to attain the desired goal state, or acts in a manner inconsistent with the goal, striving for symbols of self-completion can be achieved through compensatory acts. Thus, one persists in goal pursuit in the face of failure in an attempt to use subsequent behavior to compensate for one's shortcomings. Expressed in Lewin's (1936) terms, experiencing failure strengthens the tension to attain the goal, leading to increased effort to compensate for having violated the goal.

The compensation principle of self-completion theory suggests an efficient, implicit assessment procedure for self-defining goals.
If one wants to know whether a person holds a certain self-defining goal, one only has to inflict a relevant incompleteness experience on that person and observe whether the person responds with respective compensatory efforts. Accordingly, to determine whether our research participants were committed to the selfdefining goal of judging women in a fair and egalitarian manner, we first forced them to make stereotypic judgments of women and then observed them to see if compensatory behavior (increased egalitarianism) was displayed. If such behaviors were displayed it would indicate that those participants had felt incomplete, suggesting a committed, self-defining goal had been present and was violated. For these individuals stereotype control should be possible not merely through a strategy of correcting for the use of a stereotype or suppressing the stereotype after it is activated but through preconscious control; they should be able to control the activation of a stereotype despite the presence of a stereotyperelevant stimulus.

\section{Study 1: Knowledge of Cultural Stereotypes and Chronic Egalitarian Goals}

Our goal in this line of research is to establish that individual differences in commitment to egalitarian goals determine whether stereotype activation can be controlled. The first step is to establish that people with high commitment (chronics) and low commitment (nonchronics) to egalitarian goals can be identified. The next step is to show that each type of person has knowledge of the cultural stereotype. The reason for this is to establish that any differences between chronics and nonchronics in stereotype activation cannot be attributed to differences in availability (e.g., Higgins, 1996) of the stereotype. Such differences in availability, or a priori knowledge of the stereotype, would serve as an alternative explanation to our assertion that where these two groups differ is in their activation of the stereotype in response to a stereotype-relevant stimulus. Thus, in Study 1 we demonstrate that chronics and nonchronics can be identified and that each group has knowledge of the stereotype, which in this case is the cultural stereotype of women.

\section{Method}

\section{Research Participants}

Fifty-three male students at the University of Konstanz participated in the two phases of Study 1. Twenty-five were chronics and 28 were nonchronics (see below for criteria used to determine chronicity) with

\footnotetext{
${ }^{3}$ Even consciously adopted goal intentions can interfere with passive processes. This occurs in two ways. First, it occurs when one intends to disrupt the passive process, such as when one adopts a goal to be nonprejudiced in order to control stereotype activation (e.g., Gollwitzer, Schaal, Moskowitz, Hammelbeck, \& Wasel, 1999). Second, it occurs when one intends to implement one goal and this results in the unintended consequence of controlling a passive process that would have otherwise occurred. For example, Uleman and Moskowitz (1994) showed that goals to attend to letter strings in a sentence prevented the unconscious activation of trait categories that normally are inferred when reading such sentences. We extend this logic by saying that the unconscious activation of stereotypic trait categories can be controlled by either of these two routes through which intent impacts on passive categorization and activation processes.
} 
regard to the goal of egalitarianism toward women. Participants received DM 10 (\$7) for their participation.

\section{Procedure}

Research participants were run in groups of 3-6. There were two phases to the study. In the first phase the degree of commitment to egalitarian goals (chronic egalitarianism toward women) was assessed. The egalitarianism assessment task was made up of several parts. First, participants rated four groups on semantic differential scales. Following a distractor task, participants next completed a questionnaire designed to induce an experience of incompleteness for people committed to egalitarianism (failing to live up to a standard of being egalitarian to women by forcing participants to give stereotypic responses). Next, participants were again asked to rate the groups on the semantic differential, ostensibly because we were interested in whether judgments were stable across time. In actuality we were interested in identifying chronics by signs of compensatory behavior in their ratings of women. This phase of the research was described as a pretest for a departmental project in which professors from the different areas of psychology (social, motivational, cognitive, etc.) were exploring themes that would be of interest to students. The second phase of Study 1 was used to assess knowledge of cultural stereotypes of women (similar to the procedure used by Devine, 1989). Participants were asked to list the content of the cultural stereotype of women while disregarding their own personal beliefs regarding the validity of the stereotype.

\section{Materials}

Knowledge of the cultural stereotype. Participants were instructed to list the content of the cultural stereotype of women, disregarding their own beliefs. They were told, "We are not interested in your own beliefs about women; we only want to know about those notions that are represented in societal beliefs." Responses were open-ended; participants had $10 \mathrm{~min}$ to record them

Semantic differential scales. Participants were asked to indicate their personal beliefs about all 4 groups through trait ratings, using a 12-point semantic differential. There were four groups (women, men, workers, academics) and 17 semantic differential scales for each group (see Eckes, 1994), with 12 of these scales being stereotype relevant for the scale assessing women. Higher scores indicated greater stereotype use.

Inducing incompleteness and measuring egalitarian goals. Incompleteness was induced by a multiple-choice test forcing participants to respond in stereotypical ways: all answers involved invoking a stereotype about women. The test included five stereotype-related situations (e.g." "A couple with a baby decides the mother will quit work and care for the child"). For each situation there were three stereotypical explanations to choose from, and participants were asked to mark the one that seemed most reasonable to them. For this example, these were

(a) Women are more likely to create a warm emotional atmosphere and build a close relationship with the child

(b) Women are talkative and able to communicate with others about feelings. This makes them more understanding

(c) Women are more sensitive and caring in their relationship with children.

Nonchronics would not violate a committed goal by answering these questions and should not experience a sense of incompleteness, and, therefore, they should not display compensatory behaviors. However, inflicting failure on chronics with respect to meeting their egalitarian goal (by forcing them to give stereotypical answers) should lead chronics to experience a sense of incompleteness and to give subsequent compensatory responses. Compensatory behavior is measured by semantic differential ratings; chronics should be especially nonstereotypical on the second testing of the semantic differential (relative to their prior responses) because they are striving to compensate for the experienced incompleteness arising from having violated a chronic goal.

\section{Results}

Participants were classified as chronics and nonchronics on the basis of whether they displayed compensatory behavior in response to being forced to act stereotypically toward women. This was computed by summing the ratings concerning judgments of women for the first semantic differential and then summing the ratings for the second semantic differential. Difference scores were computed by subtracting the sum of the first (Time 1) from the sum of the second (Time 2) testing of the semantic differential. Persons whose means on the Time 1 and Time 2 semantic differentials were not in the upper third of the rating scale (because responses in the upper third are highly stereotypical) and who displayed negative differences between Time 2 and Time 1 (becoming less stereotypical) were labeled egalitarian. These persons tried to compensate after induced incompleteness (through giving less stereotypical responses to the second semantic differential than to the first one), and their responses were not at the stereotypical end of the scale. In contrast, persons with a 0 or positive difference score were labeled nonchronics because they did not try to compensate and, therefore, failed to show evidence of experiencing incompleteness.

Two judges, blind to participants' chronicity level, coded the free responses to the cultural-stereotype-assessment task. The judges achieved an agreement level of $80 \%$ on their classifications of the responses $(\kappa=.75)$. Table 1 shows the proportion of chronics and nonchronics who listed relevant attributes in their free responses, with at least $30 \%$ consensus on an attribute. The important point to highlight is that there was not one reliable difference between chronics and nonchronics along any of the attribute categories ( $p s>.20$ ). Responses in general are best described as being equally held between chronics and nonchronics.

The findings demonstrate that nonchronics do not have more knowledge of the cultural stereotype or have stereotypes of women more available to them. This suggests that any differences between chronics and nonchronics in stereotype activation cannot be construed as occurring because of a process whereby (a) the knowl-

Table 1

Percentage of People Listing Stereotypical Traits in Their Free Responses

\begin{tabular}{lcc}
\hline \multicolumn{1}{c}{ Trait } & Chronic participants & Nonchronic participants \\
\hline Sexy/pretty & 84 & 87 \\
Unassertive & 64 & 67 \\
Tender/caring & 56 & 47 \\
Fickle & 52 & 41 \\
Irrational & 50 & 44 \\
Zickiga & 48 & 57 \\
Sensitive/empathic & 41 & 50 \\
Dependent & 37 & 44 \\
Emotional & 33 & 33 \\
\hline
\end{tabular}

a Zickig is a German word that has no direct translation in English. It is a slang word that encompasses traits such as talking loudly and frequently and acting crazy in an hysterical manner. It is a word used to describe a category of women. 
edge structures in chronics are less available (because they never learned the stereotype as well as nonchronics) or (b) the knowledge structures of chronics have atrophied, cognitively speaking, because of lack of use and the repeated suppression of their content.

\section{Study 2: The Nomological Standing of the Chronic Faimess Goal Concept}

Chronic egalitarian goals have been defined here as the selfdefining goal of producing fair and nonstereotypical judgments of women. People were labeled chronics if they experienced a sense of incompleteness when forced to act in a stereotypical manner toward the specified group. However, it remains possible that the act of making a prejudiced judgment in general is what caused incompleteness, and that what we have chosen to label as a specific goal is really a somewhat general measure of a desire to not be prejudiced.

The goal of the second study was to establish the distinctiveness of the concept of chronic egalitarianism from other relevant individual difference constructs. It is important to establish that people we identify as having controlled stereotype activation that is due to chronic fairness goals directed toward women can be differentiated from people who differ in masculinity ratings (assessed by the Freiburg Personality Inventory; FPI; Schenk, Rausche, \& Steege, 1977), people who control the use of stereotypes by acting on feelings of compunction arising from having acted in a stereotypical way, people who report that they are low in prejudice on measures that assess stereotypical beliefs, and people who have global cognitive and motivational styles that might predispose them to avoid stereotypical thoughts (low need for structure, high need for cognition). Our theoretical assumption is that what is assessed by the procedure used in Study $l$ is a commitment to the goal of judging women fairly and nonstereotypically and not other personal attributes that might be relevant to the activation of the female stereotype. In Study 1 we established that chronics are not differentiated from nonchronics in their knowledge of the cultural stereotype. In Study 2 we investigate whether chronics differ from nonchronics along a series of individual difference measures that could potentially be construed as accounting for differences in stereotype activation and use.

\section{Method}

\section{Research Participants}

Forty-six male students at the University of Konstanz participated in exchange for DM 10 (\$7). Twenty-two participants were nonchronic and 24 were chronic egalitarians.

\section{Procedure}

Participants, in groups of 5-10 persons, were asked to fill out a packet of questionnaires. The packet began with a set of demographic questions that was then followed by a series of individual difference scales. The scales were, in order, the Ambivalent Sexism Inventory (ASI; Glick \& Fiske, 1996), the Modern Sexism Scale (MSS; Swim and Cohen, 1997), the Personal Need for Structure Scale (PNS; M. M. Thompson, Naccarato, \& Parker, in press), the Need for Cognition Scale (NFC; Cacioppo, Petty, Feinstein, \& Jarvis, 1996), the personal Need for Closure Scale (NFCS; Kruglanski \& Webster, 1994), the FPI (Schenk, Rausche, \& Steege, 1977), the measure for assessing chronic fairness goals toward women used in Study 1 (semantic differential scales, followed by a multiple-choice test that forces stereotypic responses, followed by another set of responses to the semantic differential scales), and finally a measure of affect.

\section{Materials}

Semantic differential scales. These scales were the same as those used in Study 1.

Inducing incompleteness and measuring egalitarian goals. Egalitarianism was defined as in Study 1, with classification dependent on commitment to the goal of faimess to women.

Affect measure. Participants were asked to respond to a set of affective measures to rule out the possibility that chronics will have lingering negative emotional reactions after having been led to give stereotypical responses. In particular, we were interested in establishing that feelings of compunction and guilt, which have been shown in prior research to lead people to produce stereotype-free responses, are not what is motivating chronic egalitarians in our research. Having the opportunity to strive toward completeness on the second round of the semantic differential questionnaire should alleviate any feelings of guilt or negative emotions that chronics might have experienced. If guilt or negative emotions are alleviated after the participants take the second semantic differential questionnaire, those emotions cannot qualify as alternative causes of control over stereotype activation. The affective measures used were borrowed from those utilized by Devine et al. (1991).

\section{Results}

The purpose of this study was to demonstrate that chronics and nonchronics do not differ along a set of individual difference and affective variables that could potentially be used to explain differences in stereotype activation and use. Instead, chronic egalitarians are said to be distinctive because of their commitment to a goal and the experience of a sense of incompleteness when that goal is violated. If this is correct we should find no differences between chronics and nonchronics along affective measures, because chronics should no longer experience a sense of incompleteness once compensation has occurred. Having had the opportunity to compensate for the negative emotions triggered by our manipulations, chronics should be similar to nonchronics in their emotions. If, however, negative affect from the manipulations lingers in chronics (or if an a priori difference in guilt is what characterizes chronics) and drives their responses on measures that assess stereotype activation and use, then chronics and nonchronics would differ in their emotional responses. The results (see Table 2) reveal that chronics and nonchronics do not differ in levels of guilt, discomfort, threat, negativity toward others, or depression $(p s>.20)$.

Additionally, if chronics are simply reflecting a general tendency to be low in prejudice, then chronics should differ from nonchronics in responses to scales that assess prejudice by tapping stereotypical beliefs (e.g., the Modern Racism Scale in past research). In the current study we examined sexism, so stereotypical beliefs were assessed through the ASI and MSS. We did not expect chronics to be different from nonchronics in terms of their attitudes toward women as assessed by scales such as the ASI or the MSS. Rather, they should only differ in terms of their commitment to the goal to be fair to women and, thus, their readiness to act on this goal when it is activated. Consistent with this interpretation and inconsistent with the notion that chronics are merely "lower in 
Table 2

Personality, Affective, Motivational, and Prejudicial Responses as a Function of Chronicity

\begin{tabular}{lrc}
\hline & \multicolumn{2}{c}{ Chronicity } \\
\cline { 2 - 3 } Individual-difference measure & Chronic & Nonchronic \\
\hline Affective response & & \\
$\quad$ Negative other & 14.7 & 17.0 \\
Positive self & 22.9 & 20.3 \\
Guilt & 55.2 & 51.1 \\
Anxiety & 54.3 & 48.9 \\
Depression & 11.1 & 11.5 \\
Threat & 11.0 & 11.5 \\
Ambivalent Sexism Inventory & 87.1 & 86.5 \\
Modern Sexism Scale & 35.4 & 37.4 \\
Personal Need for Structure & 47.1 & 45.2 \\
Need for Closure & 171.9 & 167.8 \\
Need for Cognition & 81.4 & 82.7 \\
Freiburg Personality Inventory & & \\
Extroversion & 3.2 & 3.1 \\
Masculinity & 3.2 & 3.7 \\
Neuroticism & 3.7 & 3.6 \\
\hline
\end{tabular}

Note. The range of individual items in each of the measures, except the Freiburg Personality Inventory, is from 1 to 7 . The negative other measure of affect comprises three items, and scores range from 3 to 21 ; the positive self measure of affect comprises 6 items, and scores range from 6 to 42 ; the guilt and anxiety measures of affect comprise 9 items, and scores range from 9 to 63 ; the depression and threat measures of affect comprise 2 items, and scores range from 2 to 14; the Ambivalent Sexism Inventory has 22 items, and scores range from 22 to 154; the Modern Sexism Scale has 8 items, and scores range from 8 to 56 ; the Personal Need for Structure measure has 12 items, and scores range from 12 to 84; the Need for Closure measure has 18 items, and scores range from 18 to 126; the Need for Cognition measure has 42 items, and scores range from 42 to 294 . The Freiburg Personality Inventory consists of dichotomous items $(0=$ agree, $1=$ disagree .

prejudice generally" than nonchronics, there were no reliable differences between chronics and nonchronics on either the ASI or the MSS $(p s>.30)$.

Moreover, the motivational profile of chronics and nonchronics did not reliably differ in their scores on the PNS, NFC, or NFCS ( $p s>.37$ ). Finally, chronics and nonchronics did not reliably differ in their responses to the three dimensions (neuroticism, masculinity, extroversion) of the FPI ( $p s>.30$ ). In summary, we find no reliable differences between chronics and nonchronics on any dimension other than their display of compensatory behavior on the semantic differential. On the basis of these results we conclude that chronics are distinctly different from nonchronics because of their commitment to an egalitarian goal to be fair to women and not because of general levels of prejudice, affective reactions, or global motivational and cognitive styles. ${ }^{4}$

\section{Study 3: Controlling the "Uncontrollable"-Chronic Fairness Goals Prevent Stereotype Activation}

Having established that we can identify a group of chronic egalitarians who know the cultural stereotype as well as nonchronics and who do not differ from nonchronics in general levels of prejudicial attitudes, we can examine whether chronics' commitment to their goal enables them to control stereotype activation. Such a demonstration would allow us to distinguish this prevention of stereotype activation from previous models of stereotype control that describe the process of stereotype control as one of dissociation or debiasing due to motivated efforts to correct one's judgments (effortfully) after stereotype activation. To demonstrate the effortless nature of control over stereotype activation, precautions were taken in the current experiment to avoid the possibility that conscious processes of suppression or dissociation could account for the findings. First, an implicit measure of stereotype activation-word pronunciation following primes-was used to avoid the possibility that participants would be aware of attempts to control stereotypes. Second, the responses were called for at an interval after the presentation of the prime too short to allow

\footnotetext{
${ }^{4}$ Several reviewers of this manuscript questioned why we had not used the more established method of assessing chronicity used by Bargh and colleagues (e.g., Bargh \& Tota, 1988). The reason was that the current research is investigating chronic goal orientations, whereas past research assessing chronically accessible constructs has focused on semantic construct accessibility, not goal accessibility. It was decided, instead, to develop a new method for assessing chronic goals that draws from the literature on motivation and goal pursuit rather than to use a method designed to assess a different type of construct accessibility. However, the reviewer's intuitions that chronic goal orientations could be assessed by a task similar to that used by Bargh and Tota (1988) seemed reasonable, and it also seemed like a fine method for demonstrating the convergent validity of our self-completion method of assessing chronic goals. To investigate this issue, we conducted a test of convergent validity that examined the relationship between the compensation measure used in the experiments in this article and an open-ended assessment task that paralleled the types of procedures that have been used to assess chronically accessible semantic constructs. Forty-one participants completed two separate phases of this study. In one phase they completed a series of semantic differential scales followed by a multiple-choice test that forced them to give stereotypic responses; they then completed the semantic differential scales again (the procedure used for assessing chronicity in all the studies reported in this article). Positive and negative change scores determined whether they had compensated. In a second phase, participants filled out an open-ended goal-assessment form patterned after that used by Higgins (1989) to assess self-discrepancy. It asked, "Take a few minutes to briefly describe your current hopes and goals. Please include a description of how your hopes and goals differ from those you had while growing up." Responses were then coded for mentions of egalitarian themes toward the group in question. Of the 41 participants, 30 were classified as nonchronics on the basis of the compensation measure (failure to be incomplete following the stereotypical task); 11 were classified as chronics. Of the 41 participants, only ? spontaneously mentioned egalitarian themes toward the specified group in their descriptions of their hopes and goals (not unusually small, given that the task was unrelated to stereotyping, and these responses were simply spontaneously mentioned by the participant without being solicited in any way). Of the people who spontaneously mentioned egalitarian themes, $71 \%$ of them were people labeled chronics on the basis of the compensation measure. Of the 30 people who did not attempt to compensate (no incompleteness demonstrated), only $2(7 \%)$ spontaneously mentioned egalitarian themes when describing their goals; in contrast, 5 out of the 11 people who compensated $(46 \%)$ spontaneously mentioned egalitarian themes when describing their goals, $\chi^{2}(40, N=41)=8.5, p<.01$. The conclusion is that the compensation measure seemed to be identifying people who have chronically accessible egalitarian goals. This is evidenced by the fact that people who display compensatory behavior are much more likely, without being provoked or prompted (in that the task did not mention stereotyping or egalitarianism), to be people who list egalitarian goals toward the specific group on an open-ended, goal-assessment task.
} 
conscious processes to operate. Third, participants fully attended to the primes, so that control, although shown not to be due to conscious suppression by the first two precautions, cannot be, alternatively, attributed to divided attention.

In Study 3, evidence that observing a stereotype-relevant target need not activate the stereotype for that group was sought by using a reaction time measure that assessed control at speeds (e.g., 200 ms) where it is known (Bargh, 1997; Neely, 1977) that conscious control is not possible. If chronics show no activation of stereotypes at such speeds, we have evidence that stereotype activation was controlled for by these individuals. It also suggests that such activation is due to the preconscious use of volition-chronic egalitarian goals promote implicit control over stereotype activation. In the experiment, faces of women were presented as primes. Categorizing these primes with the label woman might serve to activate the stereotype for women, but, as our model suggests, it might not. If stereotypes are accessible, then there should be a facilitation (greater ease of responding) for participants on a subsequent word pronunciation task, but only when the words to be pronounced are relevant to the stereotype. If stereotypes are not inevitably activated, but goal dependent, there should not be a facilitation in pronouncing stereotype-relevant words. Despite being primed by female faces, chronics should not have their response times facilitated by primes.

Priming paradigms are classic procedures for researching automatic processes (Bargh, Chaiken, Govender, \& Pratto, 1992; Fazio, Sanbonmatsu, Powell, \& Kardes, 1986; Meyer \& Schvaneveldt, 1971; Neely, 1977). The paradigm stipulates that conscious control is possible only after $600 \mathrm{~ms}$ have elapsed between the presentation of a prime and a stimulus (what is called a stimulus onset asynchrony, or SOA). Processing occurring within an SOA of $600 \mathrm{~ms}$ cannot be consciously controlled. Thus, automatic activation and preconscious control can be evidenced by examining responses at an SOA of $200 \mathrm{~ms}$. If control is only possible through the effortful process of correction, then chronics and nonchronics would not differ in their response latencies when the SOA was $200 \mathrm{~ms}$ : Chronics would show the facilitation of response times that nonchronics exhibit. However, chronics and nonchronics would differ at an SOA of $1,500 \mathrm{~ms}$, a time frame in which effortful control could be used. If stereotype activation was prevented, stereotype-relevant primes would be unable to facilitate response times at both $200-$ and $1,500-\mathrm{ms}$ SOAs.

\section{Method}

\section{Design and Overview}

The experiment proceeded in two phases. In the first phase participants were categorized as to whether they had a chronic goal for being fair to women (chronic egalitarians). In the second phase, those with and without chronic fairness goals to women participated in a pronunciation experiment. The research participants saw photographs of men or women followed by an attribute. Their task was to pronounce this attribute as fast as possible. The attributes were either consistent with or irrelevant to the stereotype of women and were presented at either short $(200 \mathrm{~ms})$ or long $(1,500 \mathrm{~ms})$ SOAs. Thus, there were two between-participant factors-SOA (short, long) and chronicity (chronics, nonchronics)--and there were two within-participant factors-prime (men, women in photographs) and target attributes (stereotype-consistent, stereotype-irrelevant). The dependent variable was the reaction time from the moment the trait was presented to the moment the participants began to pronounce the attribute (response latency).

\section{Research Participants}

Seventy-eight male students at the University of Konstanz, selected on the basis of chronicity scores from Phase 1, participated in Phase 2 of the experiment (41 chronics and 37 nonchronics) for DM 15 (\$10).

\section{Procedure}

In this first phase of the experiment (Phase 1) participants' chronic faimess goals toward women were assessed (as in Study 1). Phase 2 occurred 2 weeks later. Participants worked individually and were told they would see a series of (162) photographs of famous and nonfamous persons presented on a computer monitor; after each picture they would see an attribute. Of the 108 photographs of nonfamous people, 54 were of women and 54 were of men. The remaining 54 photographs were of famous people, 27 women and 27 men. Each of 18 female stereotypical attributes, 18 male stereotypical attributes, and 18 neutral attributes were paired once with a photograph of a nonfamous man, a nonfamous woman, and a famous person. The task was to pronounce each attribute as quickly as possible. The dependent variable was response latency. After all 162 pairings of attributes and pictures had been presented, research participants were debriefed.

Chronicity measure. Chronicity was measured exactly as it was in Study 1.

The pronunciation task. Research participants were exposed to a prime (a photograph of a person) followed by an attribute (personal trait). They had to pronounce the attribute as quickly as possible. Participants were told this task was being used to examine whether pictures of famous persons influence reading ability. The photographs ( 54 nonfamous men, 54 nonfamous women, and 54 famous persons) were either presented for $200 \mathrm{~ms}$ and followed immediately by attributes (SOA of $200 \mathrm{~ms}$ ) or presented for $200 \mathrm{~ms}$ and followed by attributes $1,300 \mathrm{~ms}$ later (SOA of $1,500 \mathrm{~ms}$ ). The first 10 trials were exercise trials to reduce response latency variance (Fazio, 1990). There were 172 trials total per participant, and attributes were randomly paired with pictures. The experimenter was blind to whether participants held chronic fairness goals.

Primes. The primes were photographs of nonfamous men, nonfamous women, and famous persons (e.g., Formula One champion Michael Schumacher, tennis player Boris Becker). All pictures were black-and-white photographs (to diminish color attention effects) from magazines, displayed in a passport format, in the center of the monitor and at a uniform size $(9 \times 7 \mathrm{~cm})$. The persons depicted were selected using the criterion that no attention-grabbing ornaments, glasses, hats, or clothes could be visible.

Target attributes. Six stereotypical traits for women were selected. Stereotypical attributes were determined on the basis of a pretest in which 60 students (who did not participate in the current experiment) were asked to check off stereotypical traits for women and men from a list provided for them (that was based on the attributes generated in Study 1). The 6 attributes most frequently used to describe women and never (or only once) used to describe men were used for the stereotypical attributes. These attributes, and the percentage of pretest participants who endorsed them, were (translated from German) sexy (88\%), loving (68\%), sensitive (67\%), irrational $(65 \%)$, deceptive or cunning (58\%), weak or dependent $(58 \%)$. For each trait, two synonyms were generated. This resulted in 18 female attributes. The 18 nonstereotypical attributes consisted of attributes never used to describe women and never or only once used to describe men (translated from German: colorful, sociable, flexible, fair, easygoing, optimistic, kind, reliable, just, humorless, rotten, self-critical, arrogant, lonely, impatient, inhibited, stubborn and creepy).

Apparatus. The pronunciation task was presented on a Compaq DX66 computer with a graphic card (ET 4000) to present the pictures without any 
delay. Response latency was measured by research participants' speaking into a headset microphone, thus keeping distance to the microphone constant. The program was written in Turbo Pascal 7.0 (Hewitt, 1993).

\section{Results}

Stereotype activation in this experiment is evidenced by a Prime $\times$ Target interaction for response latencies such that stereotype-relevant primes (photographs of women) lead to faster responses to stereotype-relevant attributes than when these same attributes are pronounced following nonstereotypic primes (but no such facilitation should be found for stereotype-irrelevant attributes). Stereotype control is revealed when response latencies are not faster following stereotype-relevant (versus stereotypeirrelevant) primes for either stereotype-relevant or stereotypeirrelevant attributes (no Prime $\times$ Target interaction). Nonchronics should reveal a stereotype activation pattern; chronics should not. Also, control exhibited by chronics is not consciously exerted to correct an activated stereotype. Control at an SOA of 1,500 ms could be effortful, but at an SOA of $200 \mathrm{~ms}$ it could not. Thus, a relative response latency advantage (for stereotype-relevant attributes only) for nonchronics versus chronics following stereotype-relevant primes at $200 \mathrm{~ms}$ would indicate control of stereotype activation for the chronics.

\section{Outliers and Suspicion Probes}

Suspicion regarding a contingency between the two experiments. No participants were excluded because of suspicion.

Outliers and word length effects. Response times were analyzed for extreme outliers. Response latencies more than 3 standard deviations above and below the mean in each category (e.g., prime $=$ female, target $=$ female, chronicity $=$ chronic, $\mathrm{SOA}=$ short) were excluded; $1.9 \%(n=166)$ of the response times were omitted. No category had more than $4 \%$ of the data omitted.

There was a significant correlation between word length and response latency $(r=.37, p<.05)$. However, there were not any reliable differences between word lengths in any of the categories, $F(2,46)=1.16, p>.20$, so that the correlation between word length and response latency did not affect the Prime $\times$ Chronicity $\times$ SOA analysis of variance (ANOVA; see below). The correlation between word frequency and response latency was low and not significant $(r=-.17, p=.39)$.

\section{Chronic Goals and Response Latency}

Chronic egalitarians should show a pattern of responses that demonstrates control over stereotype activation; nonchronics should show a pattern of responses in support of stereotype activation. Therefore, within each SOA condition a Prime $\times$ Target $\times$ Chronicity interaction is predicted. Although the same pattern should be found at both long and short SOAs, only responses from the short SOA condition can be used as evidence for control over activation.

As predicted, a significant Prime $\times$ Target $\times$ Chronicity interaction was found for the short-SOA condition, $F(1,38)=6.13$, $p<.02$. The Prime $\times$ Target interaction for nonchronics showed a significant activation pattern, $F(1,16)=16.87, p<.01$. Stereotype-relevant target attributes following stereotypical primes ( $M=504 \mathrm{~ms}$ ) were pronounced more quickly than stereotype- relevant target attributes following stereotype-irrelevant primes $(M=530 \mathrm{~ms}), t(16)=-5.94, p<.01$ (see Table 3). No such facilitation was found for stereotype-irrelevant attributes following stereotype-relevant ( $M=526 \mathrm{~ms}$ ) versus stereotype-irrelevant $(M=526 \mathrm{~ms})$ primes, $t(16)=-0.03, p=99$. As predicted, the Prime $\times$ Target interaction for chronics was not reliable, $F(1,18)$ $=.50, p=.49$. Stereotype-relevant attributes following stereotypical primes ( $M=554 \mathrm{~ms}$ ) were not facilitated relative to the same target attributes following stereotype-irrelevant primes $(M=556$ $\mathrm{ms}), t(18)=-1.17, p=.26$. Similarly, no differences were found for stereotype-irrelevant targets following either prime type, $t(18)$ $=-0.44, p=.67$ (see Table 3).

The long-SOA condition showed a similar pattern. The predicted Prime $\times$ Target $\times$ Chronicity interaction was significant, $F(1,36)=21.75, p<.05$. The Prime $\times$ Target interaction for nonchronics showed a reliable activation pattern, $F(1,19)$ $=20.83, p<.01$. Nonchronics pronounced stereotype-relevant words more quickly after seeing photos of female $(M=535 \mathrm{~ms})$ versus male $(M=560 \mathrm{~ms}$ ) faces, $t(19)=-4.37, p<.01$, and did not differ in their responses to stereotype-irrelevant words as a function of prime type, $t(19)=-0.97, p=.35$; see Table 4 . For chronics in the long-SOA condition, the control pattern exhibited at $200 \mathrm{~ms}$ was strengthened by the increased time interval such that active suppression of stereotypical responses seemed to be evidenced, indicated by a reliable Prime $\times$ Target interaction, $F(1$, 17) $=4.32, p=.05$. Stereotype-relevant words following stereotypical primes were pronounced more slowly ( $M=606 \mathrm{~ms}$ ) than were stereotype-relevant words following stereotype-irrelevant primes $(M=600 \mathrm{~ms})$, although this difference was not reliable. Finally, responses to stereotype-irrelevant attributes did not reliably differ following stereotype-relevant versus stereotypeirrelevant primes (see Table 4).

\section{Discussion}

The results of Study 3 demonstrate that stereotype activation is goal dependent. Participants with chronic goals failed to show the classic effect of a response time facilitation for category-relevant items after the presentation of a category-relevant priming stimulus. Research participants primed with photos of female faces should respond more quickly to stereotype-relevant attributes if the face serves to prime the stereotype. This held true for nonchronics but not for chronic egalitarians, suggesting that stereotypes had not

Table 3

Response Times (in ms) to Target Attributes at Short (200 ms) Stimulus Onset Asynchrony in Experiment 3

\begin{tabular}{lcc}
\hline & \multicolumn{2}{c}{ Prime type } \\
\cline { 2 - 3 } Attribute type & Stereotypical & Irrelevant \\
\hline & Nonchronic participants \\
Stereotypical & 504 & 530 \\
Irrelevant & 526 & 526 \\
\hline & Chronic participants & \\
Stereotypical & 554 & 556 \\
Irrelevant & 542 & 543 \\
\hline
\end{tabular}


Table 4

Response Time (in ms) to Target Attributes at Long (1,500 ms) Stimulus Onset Asynchrony in Experiment 3

\begin{tabular}{lcc}
\hline & \multicolumn{2}{c}{ Prime type } \\
\cline { 2 - 3 } Attribute type & Stereotypical & Irrelevant \\
\hline & Nonchronic participants \\
Stereotypical & 535 & 560 \\
Irrelevant & 546 & 549 \\
\hline & Chronic participants \\
Stereotypical & 606 & 600 \\
Irrelevant & 578 & 583 \\
\hline
\end{tabular}

been activated for chronics. This could not be due to conscious goals exerted on the part of chronics because the difference between chronics and nonchronics was exhibited at an SOA of only $200 \mathrm{~ms}$. Thus, stereotype activation is shown to be goal-dependent, controllable by an implicit and preconsciously operating goal. Additionally, the responses of chronics at the longer time interval (a 1,500-ms SOA) revealed attempts to actively suppress the stereotype. In the next study we examine whether the inhibition of stereotypes is the mechanism through which chronics exert control over stereotype activation at the short (200-ms) SOA. A negative priming paradigm was used to examine the hypothesis that the mechanism through which stereotype activation is controlled is the preconscious activation of a goal and the subsequent preconscious inhibition of the stereotype.

\section{Existing Evidence for Control Over Stereotype Activation}

In recent years, several experiments (e.g., Blair \& Banaji, 1996; Gilbert \& Hixon, 1991; Lepore \& Brown, 1997; Locke, MacLeod, \& Walker, 1994; Macrae, Bodenhausen, Milne, Thorn, \& Castelli, 1997) have been described as addressing the question of whether Devine's (1989) failure to find a difference in stereotyping between low- and high-prejudiced people necessarily provided evidence that stereotype activation is inevitable. However, Bargh (1999) stated that in pursuing evidence disproving the postulate of automatic stereotype activation, researchers in the field have been too quick to embrace existing data in support of the conclusion (offered by the experiments listed above) that activation is controllable. For example, Locke et al. (1994) found differences between low- and high-prejudice persons in responses to words following stereotype-relevant primes. However, this was not due to differential responding to stereotype-related words but to irrelevant words. The interaction between prejudice and word type that would suggest control over stereotype activation was achieved, but it was driven by differences along a dimension that does not address stereotype control. Gilbert and Hixon (1991) similarly stated that stereotype activation is not automatic, instead asserting that it requires attentional resources. An implicit measure of activation was used: word fragment completions. People under cognitive load exposed to a member of a stereotyped group (Asians) failed to show a stereotypical bias in their word fragment completions. However, the "stereotypical" traits used in the word fragment completions were not highly consensual, as only $30 \%$ of pretest participants had to agree on a trait for it to be considered stereotypical of Asians. Thus, the stereotype of Asians in the community where the research was conducted was weakly held, and this could account for the ability of divided attention to disrupt activation.

There are other reasons to question whether control over stereotype activation has been adequately demonstrated in the extant literature. Some experiments leave open the possibility that activation does occur but is subsequently suppressed in the time between the stereotype's activation and the experimenter's assessment of activation. For example, Lepore and Brown (1997) subliminally flashed category labels for "Black people" at participants in a priming task. Low- (vs, high-) prejudice people did not subsequently use negative stereotypes in characterizing a target. However, the conclusion from such findings that stereotype activation is controllable is brought into doubt not only by the fact that there is concrete evidence that stereotypes, albeit positive stereotypes, are activated but also by the fact that the experiment does not allow one to rule out the possibility that negative stereotypes had been activated. It could be that for low-prejudice people, negative stereotypes are activated but are weaker than the positive components of the stereotype (which then overpower activated negative stereotypes at judgment). Measuring an implicit influence of a stereotype on a consciously controlled task can provide evidence of the stereotype's activation (as in Devine, 1989). However, the absence of such an influence does not need to indicate the absence of implicit activation; it only needs to indicate the activated influence failed to carry through to conscious judgments.

Macrae et al. (1997) similarly provided evidence consistent with the possibility that stereotype activation is controlled, but they assessed activation after an interval in which conscious processes could have intervened. An implicit measure of stereotype activation was used (a lexical decision task) in which responses to stereotype-relevant words should be facilitated if stereotypes are activated. However, Macrae et al. never reported the length of the time interval between the exposure to the priming stimulus and the lexical decision task. What is reported is that a stimulus was presented for $255 \mathrm{~ms}$ and was followed by a filler task that took participants in the divided-attention condition, on average, $767 \mathrm{~ms}$ to complete. At this point, more than a second had already elapsed before the lexical decision task had even begun, and this is not including the time required to make the lexical decision or the nonreported times for the interval between the prime and the filler task and the interval between the filler task and the lexical decision. ${ }^{5}$ In both Lepore and Brown (1997) and Macrae et al., the primes were presented in ways that allowed for measuring implicit stereotype activation, but activation was then assessed after conscious processing had been initiated, making it impossible to distinguish between control over stereotype activation and conscious suppression of an already activated stereotype.

\footnotetext{
${ }^{5}$ This is particularly odd given that Macrae et al. (1997) pointed out that the reason for using a 255-ms prime-presentation time is because the 1-s interval used in their previous experiment was allowing too much time to elapse if one intends to investigate automatic processes. However, the adjustment to $255 \mathrm{~ms}$ still allows for more than $1 \mathrm{~s}$ to have elapsed. An SOA of under $400 \mathrm{~ms}$ is useful for assessing automaticity if and only if the stimuli relevant to the prime are presented immediately after the prime has disappeared and a response is immediately called for.
} 
Several other experiments are similar to ours in that the researchers (a) use implicit measures of activation and (b) control for the possibility that conscious efforts to suppress stereotypes account for differences between participants (Blair \& Banaji, 1996; Fazio \& Dunton, 1997; Wittenbrink, Judd, \& Park, 1997). Blair and Banaji (1996, Experiment 3) examined whether expectancies could disrupt stereotype activation. Participants were primed by a trait (either stereotypical, counterstereotypical, or neutral), which was followed by a name (the task was to classify the name as male or female). Some participants were told to expect counterstereotypical pairings (e.g., ambitious-Betty), others were told to expect stereotypical pairings. If a stereotype was activated, responses on the task should have been facilitated (with responses assessed at speeds where conscious attempts to control responses are not possible). They found facilitation when participants had stereotypical expectancies but not when participants had counterstereotypical expectancies. However, despite this evidence consistent with the argument for control over stereotype activation, Bargh (1999) points to difficulties in examining Blair and Banaji's findings. The responses of the counterstereotypical expectancy group would ideally be compared with a no-expectancy control group, but these data were not collected. The participants from this experiment, however, had participated minutes beforehand in Blair and Banaji's Experiment 1, which used the exact same priming task but without an expectancy provided. Thus, with the same participants performing the same task, this could be construed as a control condition. If results are compared across studies, the participants were faster with stereotypical pairings when they had a counterstereotypical expectancy than when they had no expectancy. Thus, these results do not provide clear support for the idea that counterstereotypical expectancies controlled stereotype activation.

Finally, Wittenbrink et al. (1997) and Fazio, Jackson, Dunton, and Williams (1995) have also used reactions to stereotyperelevant stimuli at speeds where conscious processing cannot intervene. However, these experiments have been more focused on attitude assessment as opposed to the demonstration of control over stereotype activation. In fact, Fazio et al.'s research really cannot speak to the issue of stereotype activation, as what was measured were evaluative reactions ("good" vs. "bad" responses) to positive and negative words that were not related to the stereotype. ${ }^{6}$ This research addresses the important question of whether automatic negative evaluations are associated with stereotyped groups. However, this question is distinct from the question of whether semantic components of a stereotype (a knowledge structure) are automatically activated. Fazio et al. described an interesting prejudice-assessment tool; the ability to control negative evaluations of stereotyped groups at speeds too fast for conscious control to intervene is certainly a nonreactive way to assess prejudicial affect. Although this is not a method for demonstrating control over stereotype activation, it is potentially a way of identifying individuals who might subsequently differ in their degree of stereotype activation.

Similarly, the interesting research of Wittenbrink et al. (1997) has nothing to do with whether stereotype activation can be controlled. It was concerned with measuring implicit racial attitudes and examining whether such implicit measures correlate with more traditional explicit measures (c.g., attitude scales). Their results are relevant to the current discussion only in that they replicated Devine's (1989) finding that stereotype activation is implicitly occurring (while Wittenbrink et al. controlled for the methodological criticisms that have been levied against the Devine, 1989, experiment). However, Wittenbrink et al. did not examine the question of whether stereotype activation can be controlled or whether it varies as a function of prejudice levels. (If one wanted to reanalyze their data by dividing participants along scores on explicit measures and then examining responses to the implicit stereotyping task, it would be possible, but this would not be particularly productive because there was a $2-s$ interval between the presentation of the primes and the lexical decision task. As mentioned above, this would not allow one to draw conclusions regarding whether the stereotype had first been activated and then suppressed or whether activation had been controlled to begin with.)

\section{Preconscious Goals and Implicit Stereotype Inhibition}

Thus, since the completion of our Studies 3 and 4 in 1995, there has been a flurry of activity on the question regarding the inevitability of stereotype activation. The evidence in support of stereotype activation as inevitable has been brought into question, but so too has evidence stating activation is controllable. In the current research, like in the past research described above, we attempted to demonstrate the controllability of activation. However, we did this from a unique perspective-by examining the goals of being nonstereotypical and egalitarian (as opposed to targeting expectancies, beliefs, or divided attention). This perspective is unique not only in that it allows one to posit that goals control activation but alse in that it allows one to posit that the intention to not stereotype need not consciously operate (recall that past studies examining goal effects on stereotyping have focused on conscious processes of debiasing, or correcting, one's thoughts). Intent can be preconscious so that goals direct processes (such as stereotype activation) that typically are carried out outside the level of conscious awareness (for a discussion of this same issue in the domain of selective attention, see Moskowitz, in press; Moskowitz \& Sussman, 1999). This begs the question of how one disrupts the "automatic" links between a category and the cultural stereotypes that are associated with that category. It is posited that such control can be exerted through the preconscious inhibition of stereotypic content.

\footnotetext{
${ }^{6}$ Their research is often characterized as being concerned with stereotype activation because Fazio et al. (1995) discussed the notion of automatic stereotype activation to establish their argument that what is activated automatically is an evaluative response. However, demonstrating the ability to control the activation of negative affect in no way addresses the question of whether stereotypes have been activated. Obvious connections exist, as they both address the issue of what happens automatically on exposure to a member of a stereotyped group. The possible link from automatic evaluation to stereotype activation is through an argument raised by Fazio et al. that if a shared cultural stereotype is activated, all individuals should respond with the same pattern of evaluative responses. This presupposes that because individuals share a cultural stereotype, they share the same evaluative reactions to the category as a whole and to the individual traits that make up the category. This assumption seems unwarranted. It is possible for both the semantic content of a cultural stereotype and one's individual affective reactions to that content to be activated.
} 
Study 4: When Stereotypes Are Inhibited Rather Than Activated-A Peek Inside the Motivational Toolbox

The purpose of the following experiment was to establish that chronic egalitarianism initiates an implicit suppression of the stereotype, thus allowing the individual to control stereotype activation by inhibiting stereotypical content from coming to mind. Earlier we argued that control over stereotype activation is not due to atrophied links to the cultural stereotype, and we based this conclusion on the fact that chronics and nonchronics were equally able to report the content of the stereotype. The current experiment provides further evidence that the links between the category woman and the stereotype's defining attributes (e.g., weak, dependent, etc.) have not atrophied, demonstrating that chronics do not simply possess a deteriorated ability to access the stereotype in the face of a relevant prime. The paradigm chosen to demonstrate implicit inhibition of the stereotype by chronic egalitarians is one that is dependent on links between the category and the cultural stereotype not only existing but being accessed by the individuals who are inhibiting stereotype activation.

\section{Negative Priming and Stereotype Inhibition}

Priming effects are dependent on the assumption that attending to a stimulus leads to the categorization of the stimulus and the subsequent activation of semantic content linked to or associated with the category-spreading activation (e.g., Collins \& Loftus, 1975; Meyer \& Schvaneveldt, 1971; Neely, 1977; Posner \& Snyder, 1975). The activation then produces facilitated responses to material semantically linked to the primed category. However, does attention always yield spreading activation? Selective attention, where a particular stimulus is what is focused on in the visual field, should produce facilitation to semantically linked material (as could incidental attention to a stimulus in one's visual field). However, recent research suggests that a process perhaps better labeled spreading inhibition can be produced by attention, if attention is focused on ignoring a stimulus and the semantic content associated with it. Rather than facilitation being found in responses to words semantically linked to a target, inhibition is exhibited when words are reacted to more slowly (Neill, Valdes, \& Terry, 1995). If the presence of a prime leads to a slowdown rather than a facilitation to words linked to the primed category, it suggests that the individual is ignoring the prime and avoiding both the category and the contents linked to it. Tipper (1985) labeled this inhibition effect associated with ignored stimuli negative priming to contrast the effect with the more typical facilitation effect.

The negative priming effect is said to be dependent on the stimulus being attended to at some level (perhaps preconsciously) so that encoding of the stimulus is not interfered with (the stimulus must be perceived). However, after the to-be-ignored stimulus has been identified, the mechanism of attention serves to inhibit the processing of information related to the ignored stimulus. As Fox (1995) pointed out, this essentially makes the inhibition process described an extension of late selection (as opposed to early selection) theories of attention (see Broadbent, 1958; Deutsch \& Deutsch, 1963; Treisman \& Geffen, 1967); selecting objects to attend to (and ignore) occurs only after some initial representation has been encoded (rather than such information being filtered out before being categorized, as in early selection). Categorization of the stimulus is followed by selective attention that is focused on ignoring the stimulus and inhibiting both the category and the contents associated with it. In the case of stereotyping, categorizing a person as having "dark skin" or "female features" or "religious attire" would occur as a natural part of the preconscious processes of perception and categorization. However, the semantic content linked to the category by virtue of cultural stereotypes (violent or emotional or zealot) could be inhibited as a function of categorization rather than activated. Such inhibition would be produced by attempts to ignore and suppress the stereotype.

In a typical negative priming procedure, two prime stimuli are presented that differ along a dimension (e.g., color of the image, location on the screen, etc.) on which participants are asked to discriminate. They are asked to ignore one image (e.g., the one colored blue) and to attend to the other. As in the Stroop effect (Stroop, 1935), the instruction to ignore something affects responses to subsequent targets that are semantically associated with the ignored material. In negative priming, response latencies are slower for target stimuli that are related to the to-be-ignored prime (relative to irrelevant stimuli). In many studies the target is simply a repeated presentation of the to-be-ignored item. However, the effect also emerges when the target is a semantic associate of the ignored prime, demonstrating that semantic meaning is being inhibited; it is not merely particular responses being interfered with or particular features being ignored (e.g., Houghton \& Tipper, 1994; Tipper, 1985).

We turn next to causes of the effect. Neill et al. (1995) posited that past responses to a stimulus are stored in episodic memory. Practice with a particular response (e.g., ignoring) to a particular stimulus is facilitated over time because the presence of the stimulus can trigger the stored representations of the response without a new response's needing to be calculated on the spot. This is not unlike the logic of the auto-motive model (Bargh, 1990), where goal-directed responses are paired repeatedly with a stimulus and can, eventually, be facilitated and triggered by the presence of the stimulus. Given this logic, Neill et al. (1995) suggested that negative priming is produced in several possible ways. First, a to-beignored prime is categorized, and this implicitly activates prior responses to that prime stored in episodic memory. If the prior response tendency conflicts with the current task, the current task will be slowed down. If one's prior response tendency was to ignore a stimulus and inhibit its semantic associates and the current task is to respond to the stimulus (or its semantic associates), then there is a conflict and the implicit inhibition effect will be evidenced by a slowed response time. Second, if there is no prior response history, the instruction to ignore a stimulus can produce an inhibition process within the experimental task (as described above). Finally, if the stimulus is unfamiliar or one that perceivers have little practice with (as with the stimuli often used in cognitive psychology), the instruction to ignore a stimulus dictates that the individual rely on "slow, 'algorithmic' processing to compute the appropriate response" (Neill et al., 1995, p. 252).

In the case of negative priming and stereotype activation, practice with the response of ignoring a stereotype when faced with a member of a stereotyped group should promote the development of preconscious inhibition of stereotypic content. Being exposed to a member of a stereotyped group should activate the inhibitory response, particularly if the priming stimulus is presented as a 
to-be-ignored distractor in a negative priming study. In contrast, practice with the activation of the stereotype when faced with a member of a stereotyped group should make the very act of ignoring it and preventing activation extremely difficult and unlikely, even if it is presented as a to-be-ignored distractor. Thus, chronics and nonchronics should have a different history of reacting to stereotype-relevant targets and their semantic associates. Chronics have the links to the stereotype from the category but do not typically activate it; rather, they typically suppress it. For nonchronics, as in the Stroop effect, it is difficult to ignore semantic content simply by being asked to do so, as they have a history of activating it. Such individual differences in experience with responses to stereotype-relevant targets should affect whether the target can be ignored and its content inhibited in a negative priming task. Chronics should exhibit negative priming, and nonchronics should exhibit positive priming.

In Study 4 a paradigm was used in which a prime (a name of a woman) was ignored, and in turn its semantically associated attributes were not activated but inhibited. This negative priming paradigm allowed for a deconfounding of the atrophy explanation for a lack of stereotype activation and our explanation that posits preconscious control. Negative priming effects cannot occur if links are not being accessed-the presence of negative priming requires that links have not atrophied. Thus, Study 4 extended the findings of Study 3 by focusing on the mechanisms through which chronic egalitarians control activation. The implicit inhibition hypothesis posits that chronics inhibit stereotypical content without activation of the stereotype. This inhibition effect should always be stronger for chronics than for nonchronics. Chronics possess the same semantic associations necessary for inhibition as nonchronics do, but they additionally possess a goal to be egalitarian, triggered by relevant environmental stimuli, that initiates inhibition processes. If the goal is implicitly activated it leads to an inhibition process that prevents stereotype activation. Of course, the conscious desire to pursue egalitarian goals can also control stereotyping, but it is accomplished through the suppression of a stereotype after it has been activated (not control over activation), a point well established in the literature on motivated correction and effortful suppression of stereotypes (e.g., Devine et al., 1991; Fiske \& Neuberg, 1990; Gollwitzer \& Moskowitz, 1996; Macrae, Bodenhausen, Milne, \& Jetten, 1994; Moskowitz et al., 1996).

To demonstrate stereotype inhibition, we used a reaction time task. Primes were flashed at an SOA where conscious inhibition processes could not be occurring. Subsequent to the primes, target attributes appeared and were to be pronounced as quickly as possible. The main difference between this exercise and the paradigm used in Study 3 was that the primes were words rather than images; also, two primes were flashed simultaneously on each trial. On critical trials, rather than attending to the stereotyperelevant primes, participants were to ignore them and focus attention on the word paired with it. Additionally, rather than varying SOA, the focus here was on implicit inhibition effects, and we chose to examine only responses at an SOA of $200 \mathrm{~ms}$, where such processes could be addressed. The stereotype investigated was, as in Study 3, stereotypes toward women.

\section{Method}

\section{Participants}

Sixty-five male students at the University of Konstanz, selected on the basis of their chronicity scores from Phase 1, participated in Phase 2 of the experiment for DM $15(\$ 10)$. Five participants' data were subsequentiy excluded because of their suspicion about the nature of the experiment, resulting in a total of 25 chronics and 35 nonchronics.

\section{Design}

The experiment was a $2 \times 2 \times 2$ mixed factorial design: The withinparticipant variables were (distractor) Primes (stereotype-relevant vs. stereotype-irrelevant words) $\times$ Target Attributes (stereotype-relevant vs. stereotype-irrelevant attributes). The between-participant variable was chronicity (chronics vs. nonchronics). The dependent variable was the response latency on the pronunciation task.

\section{Procedure}

The experiment consisted of two phases, identical to those in Study 3. In the reaction time phase of the experiment, the participants were given 160 regular (and 10 practice) trials. First, a fixation cross was presented in the middle of the screen for $1,000 \mathrm{~ms}$ and was followed by two primes: One was written in red and the other was in blue. One prime was presented above the middle of the screen, the other, below (each was $2 \mathrm{~cm}$ from the center). The primes were presented simuitaneously for $200 \mathrm{~ms}$. The participants were instructed to remember the red one and to ignore the blue one for a recall test that would occur later. The primes to be recalled were always gender neutral and written in red. The distractor primes paired with the recall primes were half gender neutral and half female names, and they were always written in blue. Immediately following the primes an attribute (stereotype-relevant or stereotype-irrelevant) was presented that was written in black (the background was white for the whole procedure). The participants had to pronounce the target word as quickly as possible. As soon as the participants began to pronounce the target word, the attribute disappeared from the screen. After $2.5 \mathrm{~s}$, a word (written in black) appeared in the middle of the screen. Half the time the word was the same as the previously presented recall prime; the rest of the time new, gender-neutral words were presented. As part of the cover story that described the experiment as being concerned with recognition memory, participants had to decide if this stimulus matched the previously presented word in red they had been asked to recall. If the answer was "yes," they had to push the button marked Yes; if "no," they had to push the button marked No on the button box. The intertrial interval was $2 \mathrm{~s}$. The dependent variable was response latency, which was the time from the presentation of the target attribute to the beginning of its pronunciation. In addition, the computer recorded the data for the answers to the match/mismatch question (recognition accuracy).

The first 10 trials were practice trials with stereotype-irrelevant primes. One hundred sixty trials followed, with 40 critical trials (all had a $200-\mathrm{ms}$ SOA). On critical trials the manipulations of prime type and target attribute were arranged such that there were 10 trials associated with each pairing of the within-participant variables: 10 female name-female attribute pairs, 10 female name-neutral attribute pairs, 10 neutral word-female attribute pairs, and 10 neutral word-neutral attribute pairs. All 160 trials were randomized so that prime-attribute pairings differed for each participant. The location of the to-be-recalled and distractor primes varied randomly as well; in $50 \%$ of the trials the distractor appeared above the center of the screen, and in $50 \%$ of the trials it appeared below.

Chronicity measure. Chronicity was measured exactly as it was in Study 1.

Primes. The recall primes (gender-neutral words) were objects such as cane, book, or table. The distractor primes were gender-neutral objects and 
female names like Bettina or Angelika. We selected words that did not possess any semantic relation to the targets (or to female stereotypes) as stereotype-irrelevant distractor primes and recall primes.

Target attributes. Ten female attributes and 10 gender-neutral attributes from Study 3 were used.

Apparatus. The apparatus was the same as that used in Study 3. All letters were approximately $15 \mathrm{~mm}$ tall and easily visible for the participants. Tests indicated that the mean stimulus presentation times were accurate within $1 \mathrm{~ms}$ with a standard deviation of less than $0.1 \mathrm{~ms}$.

\section{Results}

\section{Manipulation Checks}

Suspicion regarding a contingency between the two experiments. The participants were recruited to participate in two different studies. We asked participants after the second phase of the experiment if they thought that there was a link between the two experiments and what they thought the true nature of the experiments could be. Twelve participants were suspicious regarding the contingency. The suspicions of 5 participants were correct; therefore, their data were excluded from the analyses.

Recognition of memorized information. To make sure participants had memorized the word written in red, we made the last part of each trial in the computer experiment a match/mismatch decision test. In this task, participants had to decide if the last presented stimulus matched or mismatched the previously presented word written in red. Only $419(4.0 \%)$ of the 10,400 answers given (over all participants) were incorrect answers. Chronics did not differ from nonchronics in their recognition rate, $p>.50$. All reaction time data associated with a false match/mismatch decision were excluded, because we do not know whether these participants responded incorrectly because they had focused on the distractor prime.

Outliers. Responses were analyzed for extreme outliers. Reaction times more or less than 3 standard deviations from the mean in each category were excluded (overall, $5.6 \%$ were excluded, $n=$ 582).

\section{Chronic Fairness Goals and Negative Priming Effects}

In this experiment we examined inhibition, which is reflected by a slower response to stereotype-relevant words but only when stereotype-relevant primes appear as distractors that are to be ignored. We predicted a different pattern of results for chronics and nonchronics, namely, an inhibition pattern for chronics and an activation pattern for nonchronics (faster responses to stereotyperelevant words, but only following stereotype-relevant primes). As predicted, a reliable Prime $\times$ Target Attribute $\times$ Chronicity interaction emerged, $F(1,58)=10.84, p<.01$. The Prime $\times$ Target interaction for nonchronics showed a significant activation pattern, $F(1,34)=4.67, p<.04$, whereas the Prime $\times$ Target interaction for chronics showed a significant inhibition pattern, $F(1$, 24) $=12.14, p<.01$.

Nonchronics pronounced female attributes more quickly following female primes $(M=757 \mathrm{~ms}$ ) than following gender-neutral primes $(M=783 \mathrm{~ms}), t(34)=-2.50, p<.02$, but did not differ in their speed when pronouncing gender-neutral attributes following female versus neutral primes, $t(34)=0.92, p=.36$ (see Table 5). This is consistent with the evidence from Study 3 demonstrat-
Table 5

Response Times (in ms) to Target Attributes Following a Distractor Prime (Stimulus Onset Asynchrony $=200 \mathrm{~ms}$ ) in Experiment 4

\begin{tabular}{lcc}
\hline & \multicolumn{2}{c}{ Negative prime type } \\
\cline { 2 - 3 } Attribute type & Stereotypical & Irrelevant \\
\hline & Nonchronic participants & \\
Stereotypical & 747 & 783 \\
Irrelevant & 773 & 765 \\
\hline & Chronic participants & \\
Stereotypical & 770 & 748 \\
Irrelevant & 757 & 768 \\
\hline
\end{tabular}

ing that nonchronics have stereotypes implicitly activated. Chronics, however, reveal an opposite pattern. Female attributes were pronounced more slowly following female primes $(M=770 \mathrm{~ms})$ than following neutral primes ( $M=748 \mathrm{~ms}), t(24)=3.11, p<$ .01 . However, chronics did not reliably differ in their speed when pronouncing neutral attributes following female versus neutral primes, $t(24)=-1.57, p=.3$ (see Table 5). Given that this slowdown occurs at an SOA where conscious processes of inhibition are not possible, the data reveal an implicit inhibition and preconscious control over stereotype activation due to implicitly primed chronic goals.

\section{Discussion}

This experiment was concerned with inhibition processes occurring at the activation phase of information processing. Study 3 showed that chronics control stereotype activation. The current study showed there was a preconscious inhibition of stereotypical content for chronics but not for nonchronics. This can account for the finding of Study 3, replicated here, that stereotype activation is controlled by chronic egalitarians. Instructions to ignore a stereotype-relevant cue led to implicit inhibition of information associated with that cue. The passive inhibition effect demonstrated here was produced using a negative priming procedure, a technique new to research on stereotype activation, and suggests that stereotype control in chronic egalitarians occurs because of preconsciously activated goals. Control for chronics was based on motivational processes and was not produced by an atrophy in the links between cognitive structures. The existence of negative priming effects supports the interpretation that chronics have the same cognitive representation and structure of the stereotype but differ in their goals. Implicitly activated egalitarian goals allow chronics not merely to prevent stereotypes from being activated but to inhibit the stereotype prior to activation.

\section{General Discussion}

\section{The Passive Operation of Goals}

Chronics were not facilitated in their responses to stereotyperelevant words following stereotype-relevant primes (vs. stereotypeirrelevant primes), despite the fact that responses were being made too 
quickly for conscious control. Experiment 4 found not only no facilitation for chronics, but inhibition of the stereotype. Nonchronics, in contrast, revealed activation of the stereotype; there was facilitation in responding to stereotype-relevant words (but not stereotype-irrelevant words) following stereotype-relevant (but not stereotype-irrelevant) primes. These results demonstrate that control over stereotype activation is being exerted by chronics; the failure to use stereotypes cannot be due to an effortful process of correcting or debiasing one's judgments (e.g., Gilbert \& Hixon, 1991; Neuberg, 1989; Wegener \& Petty, 1995). This would suggest a change in how terms such as intended and deliberate are used in the literature, so that they are not equated with consciousness; one can exert the will in an intentional fashion but without effortful processing. Deliberate and volitional control can be applied preconsciously, exerting effects at the level of categorization and construct activation.

In support of this logic, Moskowitz and Sussman (1999) have found that activated goals lead to perceptual sensitization, so that goal-relevant words capture and direct attention at speeds where conscious control over attention cannot operate. Goals were controlling implicit cognitive responses. An implication of this finding, as well as the findings of the current research, for stereotyping is that the intent to be nonstereotypic need not be described as the "hard choice" that one consciously and effortfully uses to overcome the impact exerted on judgments by the "easy choice" of stereotype activation and use (Fiske, 1989). Intent to be nonstereotypic can also be the dominant or easy choice so that it, and not the stereotype, operates passively. Cognitive control contributes not only to the correction of judgments but to their construction as well (e.g., Jacoby, Kelley, \& McElree, 1999; Moskowitz, Skurnik, \& Galinsky, 1999; Moskowitz \& Skurnik, 1999).

We adopt Lewin's (1936) belief that "a goal can play an essential role in the psychological situation without being clearly present in consciousness" (p. 19). This is possible because of the implicit activation of the goal by an environmental cue, an activation made possible by the links that develop between the goal construct and relevant environmental cues as the goal becomes chronically held. However, how could such automatic constructstimulus links develop? The case that we have examined is that in which chronic goals are measured as an individual difference, differentiating between people in their level of commitment to egalitarianism. According to the auto-motives model (Bargh, 1990), such differences would develop through the habitual pursuit of a goal, thus establishing strong links between the goal construct and relevant environmental cues. This model would suggest that in addition to inhibiting stereotypical content, chronics should have the goal construct activated by the presence of a stereotyperelevant prime. Indeed, Moskowitz, Salomon, and Taylor (in press) have provided evidence demonstrating that chronics (relative to nonchronics) are facilitated in their responses to words related to egalitarianism, but only after experiencing stereotyperelevant primes (and at an SOA where conscious intent could not have been activated).

This focus on individual differences in commitment to egalitarian goals as a means to control stereotype activation might lead to the inference that we advocate a return to a personality approach to prejudice. However, we do not suggest that the task when attempting to control stereotyping and prejudice is simply one of labeling bigoted versus tolerant people. Our point is that commitment to a goal can lead to preconscious control. We began exploring this issue by focusing on individual differences, but such control, theoretically, need not be limited to an individual difference approach. One can instantiate commitment to temporary goals in people without chronic differences related to goal pursuit. If temporary goals are linked to environmental cues, the strength of the association that is established between such cues and the goal can determine whether the goal is passively activated. Thus, even if a goal construct is not chronic, its activation could be surrendered to relevant environmental cues if a strong enough link was established. The goal could then direct attention and behavior unmediated by consciousness.

This logic is reflected in Lewin's (1936) account of how intentions direct behavior and Gollwitzer and Moskowitz's (1996) notion of implementation intentions as a source of commitment. Gollwitzer and Moskowitz defined such intentions as specific plans of action for attaining a goal to which the individual is committed. This connects the goal to a situational context. In this way, intent that is not chronic but is furnished with commitment (thus linking a course of action and a context) has the activation of the intent passed to the context and relevant cues (that activate the goal directly) without any further conscious intent by the individual (Gollwitzer, 1993). A result would be that any person who chooses to reject a stereotype, not just chronically tolerant people, could control stereotype activation if their goals were enforced through plans and committed intentions (e.g., Gollwitzer, Schaal, Moskowitz, Hammelbeck, \& Wasel, 1999; Moskowitz, in press).

\section{On the Inevitability of Stereotype Activation}

We have already reviewed recent social-cognitive evidence that prejudice level (beliefs and attitudes), expectancies, and disrupted attention can interfere with the accessibility of stereotype-related content (e.g., Blair \& Banaji, 1996; Lepore \& Brown, 1997). Proposals from a variety of other perspectives suggest that stereotype activation need not be construed as an inevitable event caused by the mere presence of a member of a stereotyped group. This includes our approach, which focuses on the role in this process of preconsciously operating goals and commitment. For example, the motivational perspective outlined herein predicts that passive stereotype control is dependent on the strength of the link between the adopted goal intention and the contextual cue. This focuses attention on the fact that not only the commitment to the goal but the nature of the cue should affect whether the goal is implicitly activated and, in turn, whether the stereotype is activated. As Sagar and Schofield (1980) noted:

A category, though accessible, will be elicited only by relevant perceptual events. This raises the possibility that the violent-black stereotype may bias trait attributions to persons who engage in stereotype-relevant behavior without influencing responses to those who do not .... A clearly nonaggressing black may not be considered any more aggressive than his or her white counterpart because nothing in his or her behavior brings the violent-black stereotype to mind. (p. 592)

Thus, an African American professor might activate one's semantic constructs, such as intellectual, woman, African American, or social awkwardness. This individual might also activate one's goal constructs, such as achievement, egalitarianism, or competitiveness (see Moskowitz et al., in press). The strength of the link 
between the cue and these various constructs would affect what is activated and how the person is categorized. Not all cues should be expected to activate the stereotype, as the link to an alternative representation may be more dominant (see McArthur \& Baron's, 1983, discussion of affordances). Similarly, not all cues should be expected to activate the goal construct as activation is dependent on the links developed between the stimulus and one's goals (see Lewin's, 1936, discussion of valence). Gilbert and Hixon (1991) raised this issue when pointing out the distinction between representing a member of a stereotyped group through a verbal label (the words Black man) or through a picture or interaction. When we observe people (rather than read about them), there does not need to be activation of the stereotype for each of the many groups to which they belong. However, such activation might be hard to avoid when presented with a verbal label explicitly mentioning one of those groups. ${ }^{7}$

There are reasons to posit that stereotype activation is controllable other than the fact that some types of stimuli, such as linguistic labels, promote activation, whereas other stimuli do not. Logan (1989) found that with practice, a process once considered automatic (the Stroop effect) can be controlled. Similarly, Wegner (1994) showed that inhibitory processes can be overlearned and automatized. Skurnik and Moskowitz (1999) found that the socalled automatic tendency to encode all statements as true (and only subsequently and with cognitive effort correct this with a false label for false information) could be interfered with and controlled through practice. Bargh $(1994,1997)$ asserted that automaticity and control need not be conceived of as opposing poles but can run separately (see also Moskowitz et al., 1999). Thus, practice with and the habitualization of nonstereotypical responses (such as forming counterstereotypical expectancies, as suggested by Blair \& Banaji, 1996) should be another successful procedure for controlling stereotype activation.

\section{On the Nature of Stereotype Control}

For over a decade, psychologists have focused on the control and suppression of stereotype use. Several strategies for inhibiting stereotype use have been examined:

1. providing clear and diagnostic counterstereotypical behavior from a member of a stereotyped group that forces perceivers to individuate and attend to stereotype-inconsistent information (e.g., Locksley, Borgida, Brekke, \& Hepburn, 1980; Moskowitz, 1996),

2. providing goals (e.g., Fiske \& Neuberg, 1990; Jones \& Thibaut, 1958; Kruglanski \& Freund, 1983; Tetlock, 1985) that serve to similarly promote a movement away from heuristic information processing to systematic evaluations of members of stereotyped groups, and

3. instructing individuals to suppress stereotypic thoughts (e.g., Monteith, Sherman, \& Devine, 1998; Macrae, Bodenhausen, et al., 1994). These strategies suggest that control is exerted through effortful processing and the intention to curb one's use of stereotypes after stereotypes have been activated. Our data are not inconsistent with this notion that goals can lead to the effortful debiasing of judgments after the passive activation of a stereotype. Even nonchronics should be able to control stereotyping if they have a goal that promotes elaborate processing. However, our data further demonstrate that stereotype activation can be controlled through goals. This means that we can move beyond the notion of control as a process of dissociation. Volition may play a role at both the conscious and the preconscious levels, preventing stereotype activation.

Why is it that these conclusions differ from Devine (1989)? Prejudice level in that research was assessed through a beliefs scale, and perhaps such measures do not adequately assess commitment to egalitarian and nonprejudiced goals. Thus, even Devine's participants who claimed to be low in prejudice were, interestingly, shown to have had their stereotypes activated. These people have apparently learned socially transmitted information (the stereotype) and could very well reject those stereotypical beliefs, yet they may not be committed enough to, or have had enough time to, habitualize that rejection. Thus, although there is clearly a class of people whom we can classify as bigots, the discussion here concerns people who are not bigoted. Nonbigots are those who reject stereotypes, and it is suggested that they fall into several categories. They may range from those who cannot prevent stereotype activation despite rejecting stereotypical beliefs (but can correct for their use of stereotypes in later judgments) to those who habitualize rejection and fail to have stereotypes activated. For the former, stereotype use is the easy choice; for the latter, chronic fairness goals are dominant. This extension of the dissociation model is important because it suggests ways to control stereotype use that are not subject to some of the limitations of the debiasing (or dissociation) strategy. Debiasing fails if the processing system is taxed. It also fails if one is unaware of one's biases and, thus, unmotivated to correct them. Rationalizations and avoidance strategies help people maintain such unawareness so that they do not need to face their biases and deal with the compunction and guilt such awareness would invoke (see Allport's, 1954, discussion of inner conflict). ${ }^{8}$ Additionally, even when a conscious attempt to suppress a stereotype succeeds, it can lead to rebound effects so that stereotypes are used in subsequent judgments (e.g., Macrae, Bodenhausen, et al., 1994).

\section{Conclusion}

In stating that stereotype activation can be controlled, we do not wish to undermine the position that stereotypes can be activated and operate outside of awareness, that this happens with great efficiency and without conscious intent to activate or use them. Stereotypes are pervasive, passive, and functional (see, e.g., Macrae, Milne, \& Bodenhausen, 1994). This, however, does not mean that activation is beyond control. Activation of stereotypes can be

\footnotetext{
${ }^{7}$ As Gilbert and Hixon (1991) stated, "The Sufis teach that 'If a pickpocket meets a holy man, he will see only his pockets" (p. 511) but "when a pickpocket reads the words holy man, he will probably think of a great deal more than pockets-and in so doing, he will reveal little about how pickpockets construe holy men in their day-to-day lives" (516).

${ }^{8}$ People often are not aware they use stereotypes, making stereotypes difficult to control (Hepburn \& Locksley, 1983). This can create a sense that stereotyping is not really something that perceivers need to worry about in their personal dealings: They need not attempt to correct or adjust their judgments because they are not aware that they are influenced by stereotypes (e.g., McConahay \& Hough, 1976). It allows perceivers to relegate stereotyping to the domain of an imagined "group of racists" rather than bother with debiasing their own responses.
} 
controlled by more dominant responses, in this case, egalitarian goals. However, this requires commitment to such a goal, and without commitment, stereotype activation will be likely to occur.

In discussing stereotype control, Macrae, Bodenhausen, and Milne (1995) suggested that people, as targets of perception, are multifaceted and complex. Many conceptions of others may be activated when categorizing, and as Allport (1954, p. 21) stated, the dominant social category will be what is used. This may be the stereotype, but for people with chronic egalitarian goals, the goal may be what is dominant, and it could win this metaphorical, preconscious race to capture the stimulus. Stereotypes are habits that develop by reaching too often into the cognitive toolbox to ease the task of impression formation. They can, however, be broken by using motivation to direct the perceiver to find his or her tools elsewhere. Commitment to egalitarian goals can prevent stereotype activation when making inferences from social information.

\section{References}

Ach, N. (1935). Analyse des Willens [Analysis of the Will]. In E. Abderhalden (Ed.), Handbuch der biologischen Arbeitsmethoden (Vol. 6). Berlin, Germany: Urban \& Schwarzenberg.

Allport, G. W. (1954). The nature of prejudice. Reading, MA: AddisonWesley.

Bargh, J. A. (1989). Conditional automaticity: Varieties of automatic influence in social perception and cognition. In J. S. Uleman \& J. A. Bargh (Eds.), Unintended thought (pp. 3-51). New York: Guilford Press.

Bargh, J. A. (1990). Auto-motives: Preconscious determinants of social interaction. In E. T. Higgins \& R. M. Sorrentino (Eds.), Handbook of motivation and cognition (Vol. 2, pp. 93-130). New York: Guilford Press.

Bargh, J. A. (1994). The four horsemen of automaticity: Awareness, intention, efficiency, and control in social cognition. In R. S. Wyer, Jr., \& T. K. Srull (Eds.), Handbook of social cognition: Vol. 1. Basic processes (2nd ed., pp. 1-40). Hillsdale, NJ: Erlbaum.

Bargh, J. A. (1997). Automaticity of everyday life. In R. S. Wyer, Jr. (Ed.), Advances in social cognition: Vol. 10. The automaticity of everyday life (pp. 1-61). Mahwah, NJ: Erlbaum.

Bargh, J. A. (1999). The cognitive monster: The case against the controllability of automatic stereotype effects. In S. Chaiken \& Y. Trope (Eds.), Dual process theories in social psychology (pp. 361-382). New York: Guilford Press.

Bargh, J. A., Chaiken, S., Govender, R., \& Pratto, F. (1992). The generality of the automatic attitude activation effect. Journal of Personality and Social Psychology, 62, 893-912.

Bargh, J. A., \& Gollwitzer, P. M. (1994). Environmental control of goaldirected action: Automatic and strategic contingencies between situations and behavior. In W. Spaulding (Ed.), Nebraska Symposium on Motivation (Vol. 41, pp. 71-124). Lincoln: University of Nebraska Press.

Bargh, J. A., Gollwitzer, P. M., Chai, A., \& Barndollar, K. (1998). Bypassing the will: Nonconscious self-regulation through automatic goal pursuit. Manuscript submitted for publication.

Bargh, J. A., \& Tota, M. E. (1988). Context-dependent processing in depression: Accessibility of negative constructs with regard to self but not others. Journal of Personality and Social Psychology, 54, 924-939.

Blair, I. V., \& Banaji, M. R. (1996). Automatic and controlled processes in stereotype priming. Journal of Personality and Social Psychology, 70 , $1142-1163$.

Broadbent, D. E. (1958). Perception and communication. London: Pergamon Press.
Bruner, J. S. (1957). On perceptual readiness, Psychologicat Review, 64, 123-152.

Brunstein, J. C., \& Gollwitzer, P. M. (1996). Effects of failure on subsequent performance: The importance of self-defining goals. Journal of Personality and Social Psychology, 70, 395-407.

Cacioppo, J. T., Petty, R. E., Feinstein, J. A., \& Jarvis, B. G. (1996). Dispositional differences in cognitive motivation: The life and times of individuals varying in need for cognition. Psychological Bulletin, 119 , 197-253.

Chartrand, T. L., \& Bargh, J. A. (1996). Automatic activation of impression formation goals: Nonconscious goal priming reproduces effects of explicit task instructions. Journal of Personality and Social Psychology, 71, 464-478.

Collins, A. M., \& Loftus, E. F. (1975). A spreading activation theory of semantic processing. Psychological Review, 5, 85-88.

Deutsch, J. A., \& Deutsch, D. (1963). Attention: Some theoretical considerations. Psychological Review, 70, 80-90.

Devine, P. G. (1989). Stereotypes and prejudice: Their automatic and controlled components. Journal of Personality and Social Psychology, 56, 5-18.

Devine, P. G., Monteith, M. J., Zuwerink, J. R., \& Elliot, A. J. (1991). Prejudice with and without compunction. Journal of Personality and Social Psychology, 60, 817-830.

Eckes, T. (1994). Features of men, features of women: Assessing stereotypic beliefs about gender subtypes. British Journal of Social Psychology, 33, 107-123.

Fazio, R. H. (1990). A practical guide of the use of response latency in social psychological review. In C. Hendrick \& M. S. Clark (Eds.), Research methods in personality and social psychology (pp. 74-97). Newbury Park, CA: Sage.

Fazio, R. H., \& Dunton, B. C. (1997). Categorization by race: The impact of automatic and controlled components of racial prejudice. Journal of Experimental Social Psychology, 33, 451-470.

Fazio, R. H., Jackson, J. R., Dunton, B. C., \& Williams, C. J. (1995). Variability in automatic activation as an unobtrusive measure of racial attitudes: A bona fide pipeline? Joumal of Personality and Social Psychology, 69, 1013-1027.

Fazio, R. H., Sanbonmatsu, D. M., Powell, M. C., \& Kardes, F. R. (1986). On the automatic activation of attitudes. Journal of Personality and Social Psychology, 50, 229-238.

Fiske, S. T. (1989). Examining the role of intent: Toward understanding its role in stereotyping and prejudice. In J. S. Uleman \& J. A. Bargh (Eds.), Unintended thought (pp. 253-283). New York: Guilford Press.

Fiske, S. T., \& Neuberg, S. L. (1990). A continuum of impression formation, from category-based to individuating processes: Influences of information and motivation on attention and interpretation. Advances in Experimental Social Psychology, 23, 1-74.

Fox, E. (1995). Negative priming from ignored distractors in visual selection: A review. Psychonomic Bulletin \& Review, 2, 145-173.

Gilbert, D. T., \& Hixon, J. G. (1991). The trouble of thinking: Activation and application of stereotypic beliefs. Journal of Personality and Social Psychology, 60, 509-517.

Glick, P., \& Fiske, S. T. (1996). The Ambivalent Sexism Inventory: Differentiating hostile and benevolent sexism. Journal of Personality and Social Psychology, 70, 491-512.

Gollwitzer, P. M. (1993). Goal achievement: The role of intentions. In W. Stroebe \& M. Hewstone (Eds.), European Review of Social Psychology, Vol. 4 (pp. 141-185). Chichester, England: Wiley.

Gollwitzer, P. M., \& Kirchhof, O. (1998). The willful pursuit of identity. In J. Heckhausen \& C. S. Dweck (Eds.), Motivation and self-regulation across the life span (pp. 389-423). New York: Cambridge University Press.

Gollwitzer, P. M., \& Moskowitz, G. B. (1996). Goal effects on action and cognition. In E. T. Higgins \& A. W. Kruglanski (Eds.), Social psychol- 
ogy: Handbook of basic principles (pp. 361-399). New York: Guilford Press.

Gollwitzer, P. M., Schaal, B., Moskowitz, G. B., Hammelbeck, H. J. P., \& Wasel, W. (1999). Implementation effects on stereotype activation. Unpublished manuscript.

Gollwitzer, P. M., \& Wicklund, R. A. (1985). The pursuit of self-defining goals. In J. Kuhl \& J. Beckmann (Eds.), Action control: From cognition to behavior. Heideiberg, Germany: Springer-Verlag.

Gollwitzer, P. M., Wicklund, R. A., \& Hilton, J. L. (1982). Admission of failure and symbolic self-completion: Extending Lewinian theory. Journal of Personality and Social Psychology, 43, 358-371.

Hamilton, D. L., \& Sherman, J. (1994). Stereotypes. In R. S. Wyer, Jr., \& T. K. Srull (Eds.), Handbook of social cognition: Vol. 2. Applications (2nd ed., pp. 1-68). Hillsdale, NJ: Erlbaum.

Hepburn, C., \& Locksley, A. (1983). Subjective awareness of stereotyping: Do we know when our judgments are prejudiced? Social Psychology Quarterly, 46, 311-318.

Hewitt, L. C. (1993). Turbo Pascal in the lab: A hands-on approach (Version 7.0) [Computer programming language]. Menlo Park, CA: Benjamin/Cummings.

Higgins, E. T. (1989). Knowledge accessibility and activation: Subjectivity and suffering from unconscious sources. In J. S. Uleman \& J. A. Bargh (Eds.), Unintended thought (pp. 75-123). New York: Guilford Press.

Higgins, E. T. (1996). Knowledge activation: Accessibility, applicability, and salience. In E. T. Higgins \& A. W. Kruglanski (Eds.), Social psychology: Handbook of basic principles (pp. 133-168). New York: Guilford Press.

Higgins, E. T., Rholes, W. S., \& Jones, C. R. (1977). Category accessibility and impression formation. Journal of Experimental Social Psychology, 13, 141-154.

Houghton, G., \& Tipper, S. P. (1994). A model of inhibitory mechanisms in selective attention. In D. Dagenbach \& T. H. Carr (Eds.), Inhibitory processes in attention, memory, and language (pp. 53-112). San Diego, CA: Academic Press.

Jacoby, L., Kelley, C. M., \& McElree, B. D. (1999). The role of cognitive control: Early selection versus late correction. In S. Chaiken \& Y. Trope (Eds.), Dual process theories in social psychology (pp. 383-400). New York: Guilford Press.

Jones, E. E., \& Thibaut, J. W. (1958). Interaction goals as bases of inference in interpersonal perception. In L. Petrullo \& R. Tagiuri (Eds.), Person perception and interpersonal behavior (pp. 151-178). Stanford, CA: Stanford University Press.

Kruglanski, A. W. (1996). Goals as knowledge structures. In P. M. Gollwitzer \& J. A. Bargh (Eds.), The psychology of action: Linking cognition and motivation to behavior (pp. 599-618). New York: Guilford Press.

Kruglanski, A. W., \& Freund, T. (1983). The freezing and unfreezing of lay-inferences: Effects on impressional primacy, ethnic stereotyping, and numerical anchoring. Journal of Experimental Social Psychology, 19, 448-468.

Kruglanski, A. W., \& Webster, D. M. (1994). Individual differences in need for cognitive closure. Journal of Personality and Social Psychology, 67, 1049-1062.

Lepore, L., \& Brown, R. (1997). Category and stereotype activation: Is prejudice inevitable? Journal of Personality and Social Psychology, 72, 275-287.

Lewin, K. (1936). Principles of topological psychology. New York: McGraw-Hill

Locke, V., MacLeod, C., \& Walker, I. (1994). Automatic and controlled activation of stereotypes: Individual differences associated with prejudice. British Journal of Social Psychology, 33, 29-46.

Locksley, A., Borgida, E., Brekke, N., \& Hepburn, C. (1980). Sex stereotypes and social judgment. Journal of Personality and Social Psychology, 39, 821-831.

Logan, G. D. (1989). Automaticity and cognitive control. In J. S. Uleman
\& J. A. Bargh (Eds.), Unintended thought (pp. 52-74). New York: Guilford Press.

Macrae, C. N., Bodenhausen, G. V., \& Milne, A. B. (1995). The dissection of selection in person perception: Inhibitory processes in social stereotyping. Journal of Personality and Social Psychology, 69, 397-407.

Macrae, C. N., Bodenhausen, G. V., Milne, A. B., \& Jetten, J. (1994). Out of mind but back in sight: Stereotypes on the rebound. Journal of Personality and Social Psychology, 67, 808-817.

Macrae, C. N., Bodenhausen, G. V., Milne, A. B., Thorn, T. M. J., \& Castelli, L. (1997). On the activation of social stereotypes: The moderating role of processing objectives. Journal of Experimental Social Psychology, 33, 471-489.

Macrae, C. N., Milne, A. B., \& Bodenhausen, G. V. (1994). Stereotypes as energy-saving devices: A peek inside the cognitive toolbox. Journal of Personality and Social Psychology, 66, 37-47.

McArthur, L. Z., \& Baron, R. (1983). Toward an ecological theory of social perception. Psychological Review, 90, 215-238.

McConahay, J. B., Hardee, B. B., \& Batts, V. (1981). Has racism declined? It depends on who's asking and what is asked. Journal of Conflict Resolution, 25, 563-579.

McConahay, J. B., \& Hough, J. (1976). Symbolic racism. Joumal of Social Issues, 32, 23-45.

Meyer, D. E., \& Schvaneveldt, R. W. (1971). Facilitation in recognizing pairs of words: Evidence of a dependence between retrieval operations. Journal of Experimental Psychology, 90, 227-234.

Monteith, M. J., Sherman, J. W., \& Devine, P. G. (1998). Suppression as a stereotype control strategy. Personality and Social Psychology Review, 2, 63-82.

Moskowitz, G. B. (1996). The mediational effects of attributions and information processing in minority social influence. British Journal of Social Psychology, 35, 47-66.

Moskowitz, G. B. (in press). On preconscious control. In G. B. Moskowitz (Ed.), Cognitive social psychology: On the tenure and future of social cognition. Mahwah, NJ: Erlbaum.

Moskowitz, G. B., Salomon, A. R., \& Taylor, C. M. (in press). Implicit control of stereotype activation through the preconscious operation of egalitarian goals. Social Cognition.

Moskowitz, G. B., \& Skurnik, I. (1999). Contrast effects as determined by the type of prime: Trait versus exemplar primes initiate processing strategies that differ in how accessible constructs are used. Journal of Personality and Social Psychology, 76, 911-927.

Moskowitz, G. B., Skurnik, I., \& Galinsky, A. (1999). The history of dual process notions: The future of preconscious control. In S. Chaiken \& Y. Trope (Eds.), Dual process theories in social psychology (pp. 12-36). New York: Guilford Press.

Moskowitz, G. B., \& Sussman, K. (1999). Compensatory cognition: The implicit regulation of goals. Manuscript submitted for publication.

Moskowitz, G. B., Wasel, W., Gollwitzer, P. M., \& Schaal, B. (July, 1996). Deploying egalitarianism volitionally inhibits nonconscious effects of stereotypes: Unconsciousiy and chronically killing stereotypes. Poster session presented at the 8th Annual Conference of the American Psychological Society, San Francisco, CA.

Myrdal, G. (1944). An American dilemma. New York: Harper.

Neely, J. (1977). Semantic priming and retrieval from lexical memory: Roles of inhibitionless spreading activation and limited-capacity attention. Journal of Experimental Psychology: General, 106, 226-254.

Neill, W. T., Valdes, L. A., \& Terry, K. M. (1995). Selective attention and the inhibitory control of cognition. In F. N. Dempster \& C. J. Brainerd (Eds.), Interference and inhibition in cognition (pp. 207-261). San Diego, CA: Academic Press.

Neuberg, S. L. (1989). The goal of forming accurate impressions during social interactions: Attenuating the impact of negative expectancies. Journal of Personality and Social Psychology, 56, 374-386.

Posner, M. I., \& Snyder, C. R. R. (1975). Attention and cognitive control. 
In R. L. Solso (Ed.), Information processing and cognition: The Loyola symposium (pp. 55-85). Hillsdale, NJ: Erlbaum.

Sagar, H. A., \& Schofield, J. W. (1980). Racial and behavioral cues in Black and White children's perceptions of ambiguously aggressive acts. Journal of Personality and Social Psychology, 39, 590-598.

Schenk, J., Rausche, A., \& Steege, F. W. (1977). On the structure of the Freiburg Personality Inventory (FPI). Zeitschrift fuer Experimentelle und Angewandte Psychologie (Journal of Experimental and Applied Psychology), 24, 492-509.

Skurnik, I., \& Moskowitz, G. B. (1999). Metacognition and the illusion of truth. Manuscript submitted for publication.

Stangor, C., \& Lange, J. E. (1994). Mental representations of social groups: Advances in understanding stereotypes and stereotyping. In M. P. Zanna (Ed.), Advances in experimental social psychology (Vol. 26, pp. 357416). New York: Academic Press.

Stone, J., Wiegand, A. W., Cooper, J., \& Aronson, E. (1997). When exemplification fails: Hypocrisy and the motive for self-integrity. Journal of Personality and Social Psychology, 72, 54-65.

Stroop, J. R. (1935). Studies of interference in serial verbal reactions. Journal of Experimental Psychology, 18, 643-662.

Swim, J. K., \& Cohen, L. L. (1997). Overt, covert, and subtle sexism: A comparison between the Attitudes Toward Women and Modern Sexism Scales. Psychology of Women Quarterly, 21, 103-118.

Tetlock, P. E. (1985). Accountability: A social check on the fundamental attribution error. Social Psychology Quarterly, 48, 227-236.

Thompson, E. P., Roman, R. J., Moskowitz, G. B., Chaiken, S., \& Bargh, J. A. (1994). Accuracy motivation attenuates covert priming: The systematic reprocessing of social information. Journal of Personality and Social Psychology, 66, 474-489.

Thompson, M. M., Naccarato, M. E., \& Parker, K. (in press). Measuring cognitive needs: The development and validation of the Personal Need for Structure and Personal Fear of Invalidity Scales. In G. B. Moskowitz. (Ed.). Cognitive social psychology: On the tenure and future of social cognition. Mahwah, NJ: Erlbaum.

Tipper, S. P. (1985). The negative priming effect: Inhibitory priming by ignored objects. Quarterly Journal of Experimental Psychology: Human Experimental Psychology, 37A, 571-590.

Treisman. A., \& Geffen, G. (1967). Selective attention: Perception or response? Quarterly Journal of Experimental Psychology, 19, 1-17.

Uleman, J. S., \& Moskowitz, G. B. (1994). Unintended effects of goals on unintended inferences. Journal of Personality and Social Psychology, 66, 490-501.

Von Hippel, W., Sekaquaptewa, D., \& Vargas, P. (1995). On the role of encoding processes in stereotype maintenance. In M. P. Zanna (Ed.), Advances in experimental social psychology (Vol. 27, pp. 177-254). New York: Academic Press.

Wegener, D. T., \& Petty, R. E. (1995). Flexible correction processes in social judgment: The role of naive theories in corrections for perceived bias. Journal of Personality and Social Psychology, 68, 36-51.

Wegner, D. M. (1994). Ironic processes of mental control. Psychological Review, 101, 34-52.

Wicklund, R. A., \& Gollwitzer, P. M. (1982). Symbolic self-completion. Hillsdale, NJ: Exlbaum.

Wittenbrink, B., Judd, C. M., \& Park, B. (1997). Evidence for racial prejudice at the implicit level and its relationship with questionnaire measures. Journal of Personality and Social Psychology, 72, 262-274. 